\title{
Variabilidade genética do umbuzeiro no Semi-Árido brasileiro, por meio de marcadores AFLP
}

\author{
Carlos Antonio Fernandes Santos(1), Marciene Amorim Rodrigues ${ }^{(1)}$ e Maria Imaculada Zucchi(2)
}

(1)Embrapa Semi-Árido, Caixa Postal 23, CEP 56302-970 Petrolina, PE. E-mail: casantos@cpatsa.embrapa.br, marciene.rodrigues@cpatsa. embrapa.br (2)Instituto Agronômico, Avenida Barão de Itapura, no 1.481, Centro, CEP 13020-902 Campinas, SP. E-mail: mizucchi@esalq.usp.br

\begin{abstract}
Resumo - O objetivo deste trabalho foi avaliar a distribuição da variabilidade genética do umbuzeiro (Spondias tuberosa), no Semi-Árido brasileiro, por meio de marcadores AFLP, para subsidiar estratégias de prospecção e conservação da espécie. Foram analisados 68 indivíduos de umbuzeiro de 15 ecorregiões, pelo dendrograma UPGMA e pela dispersão em escala multidimensional (MDS), com o coeficiente de Jaccard de 141 bandas polimórficas de AFLP. A análise da variância molecular foi realizada pela decomposição total entre e dentro das regiões ecogeográficas. O dendrograma apresentou valor cofenético de 0,96, e o gráfico MDS apresentou 0,25 para a falta de ajustamento. A variabilidade genética do umbuzeiro foi estimada em 0,3138 , o que indica grande variação entre os grupos de indivíduos. Agrupamentos específicos foram observados em seis regiões ecogeográficas, enquanto nas demais regiões observaram-se pares entre alguns indivíduos, sem formação de agrupamentos específicos por local de amostragem, o que indica que a variabilidade genética do umbuzeiro não está uniformemente distribuída no Semi-Árido. Sugerem-se estratégias para o estabelecimento de maior número de áreas para conservação in situ ou amostragens de menor número de indivíduos, em várias unidades de paisagens, para conservação ex situ da variabilidade genética do umbuzeiro.
\end{abstract}

Termos para indexação: Spondias tuberosa, análise multivariada, análise de variância molecular, dendrograma, escala multidimensional.

\section{Genetic variability of umbu trees in Brazilian Semi-Arid region, based on AFLP markers}

\begin{abstract}
The objective of this work was to evaluate the genetic variability distribution of umbu tree (Spondias tuberosa), within Brazilian Semi-Arid region, based on AFLP markers, in order to suggest prospecting and preservation strategies for this species. Sixty-eight umbu trees of 15 ecogeographic regions were analyzed for 141 polymorphic AFLP bands, through the UPGMA dendrogram and the multidimensional scaling (MDS), based on Jaccard's coefficient. Analysis of molecular variance was accomplished by total decomposition among and within ecogeographic regions. The dendrogram presented co-phenetic value of 0.96 , while the MDS presented 0.25 for the badness-of-fit. Umbu genetic variability was estimated in 0.3138 , indicating a large variance among individual groups. Specific clusters were observed in six ecogeographic regions, and some individual pairs were observed in the other regions, with no specific clustering by sampling place, which indicates that the genetic variability of umbu tree is not uniformly distributed within Brazilian Semi-Arid. Strategies are suggested to set a larger number of protection areas for in situ conservation, or a smaller number of umbu individuals sampled, in various ecoregion units, for ex situ genetic variability conservation of this species.
\end{abstract}

Index terms: Spondias tuberosa, multivariate analyses, analysis of molecular variance, dendrogram, multidimensional scaling.

\section{Introdução}

O umbuzeiro (Spondias tuberosa Arruda) é uma Anacardiacea, do gênero Spondias, que é formado por, aproximadamente, 17 espécies, das quais sete distribuídas na América Tropical e, aproximadamente, dez na Ásia Tropical (Miller \& Schaal, 2005). Não existem relatos da ocorrência do umbuzeiro em outras regiões do planeta, que é uma árvore xerófita endêmica do Semi-
Árido brasileiro (Prado \& Gibbs, 1993). É uma espécie predominantemente de fecundação cruzada, com taxa de cruzamento aparente de $74 \%$ (Souza, 2000).

Esta Anacardiacea, pela sua adaptação ao SemiÁrido e aproveitamento secular, tem desempenhado importante papel agrossocioeconômico, e o extrativismo de seu fruto é bastante significativo na composição da renda familiar para algumas comunidades da região. 
Contudo, o extrativismo de frutos tem apresentado declínio constante, ao longo dos últimos 20 anos (Santos et al., 2005).

Um dos aspectos mais importantes e difíceis para a prospecção de recursos genéticos vegetais é a definição de estratégias de amostragem para espécie numa região. Como resultado, apenas uma amostra da variação que ocorre na natureza pode ser coletada. O desafio é estabelecer procedimentos de amostragem com a maior quantidade de informação útil sobre a variação genética, dentro de um número limitado de amostras. Uma estratégia de amostragem deve considerar aspectos taxonômicos, geográficos e ecológicos. Esse processo é definido como prospecção ecogeográfica (Maxted et al., 1995).

A ausência de relações entre distância genética e regiões ecogeográficas tem sido reportada quanto à Artocarpus heterophyllus (Jagadeesh et al., 2007), Solanum tuberosum (Rio et al., 2004) e Stipa lagascae (Visser \& Reheul, 2001), enquanto relações positivas entre distâncias genéticas e regiões ecogeográficas têm sido reportadas para populações de Cicer arietinum (Abbo et al., 2003), Stylosanthes macrocephala (Barros et al., 2005), Heritiera littoralis (Jian et al., 2004), Amburana cearensis, Myracrodruon urundeuva e Schinopsis brasiliensis (Santos et al., 2007) e Brassica spp. (Watson-Jones et al., 2006). Para o umbuzeiro, Santos (1997) não encontrou relações entre distância genética e regiões ecogeográficas, por meio de caracteres fenotípicos. Deve ser destacado que caracteres fenotípicos são extremamente influenciados pelo ambiente e que trabalhos com marcadores de DNA para o umbuzeiro são inexistentes.
O advento dos marcadores de DNA abriu a possibilidade de amplos estudos da variabilidade de recursos genéticos vegetais numa dimensão nunca antes imaginável. Como destacado por Santos et al. (2007), estratégias para conservação de recursos genéticos podem ser definidas com base nas informações obtidas com os marcadores de DNA: quando a variabilidade está dentro das populações é necessária uma rede maior de áreas de preservação ambiental (APAs), para preservação in situ da variabilidade genética; quando a variabilidade está entre as regiões, ou seja, quando ocorre agrupamento de indivíduos independentemente da região de coleta, temse indicativo de que poucas APAs sejam necessárias.

O objetivo deste trabalho foi estudar a dispersão da variabilidade genética do umbuzeiro no Semi-Árido brasileiro, com base no marcador polimorfismo de comprimento de fragmentos amplificados

(AFLP-“amplified fragment length polimorphism"), para subsidiar estratégias de prospecção, preservação e utilização da variabilidade genética da espécie.

\section{Material e Métodos}

Foram analisados 68 indivíduos de umbuzeiros, amostrados em 15 regiões ecogeográficas, em sete estados do polígono da seca, assim distribuídos: em sete regiões ecogeográficas foram amostrados cinco indivíduos; nas demais, foram analisados quatro indivíduos (Tabela 1). Para definição das áreas de amostragem do umbuzeiro no Semi-Árido, adotou-se o procedimento de Santos (1997). A distância mínima de $500 \mathrm{~m}$ de uma planta para outra foi considerada na amostragem dentro de uma mesma região ecogeográfica.

Tabela 1. Regiões ecogeográficas e cidade de referência da amostragem de indivíduos de umbuzeiro, para análise da dispersão genética com base no marcador AFLP.

\begin{tabular}{lll}
\hline Região ecogeográfica & Cidade de referência & \multicolumn{1}{c}{ Indivíduos } \\
\hline Chapadas altas & Araripe, CE & A1-6, A1-7, A1-8, A1-3, A1-10 \\
Chapadas intermediárias & Pio IX, PI & B1-6, B1-7, B1-8, B1-9, B1-10 \\
Chapada Diamantina & Paramirim, BA & C2-2, C2-5, C2-6, C2-7, C2-9 \\
Planalto da Borborema & Soledade, PB & D2-6, D2-7, D2-8, D2-9, D2-10 \\
Superfícies retrabalhadas & Porteirinha, MG & E1-6, E1-7, E1-8, E1-9, E1-10 \\
Superfícies retrabalhadas & Anagé, BA & E2-3, E2-6, E2-8, E2-12 \\
Superfícies retrabalhadas & Jacobina, BA & E3-6, E3-7, E3-8 \\
Depressão sertaneja & Ichu, BA & F1-6, F1-7, F1-8, F1-9, F1-10 \\
Depressão sertaneja & Santa Cruz, RN & F5-6, F5-7, F5-8, F5-10 \\
Superfícies cársticas & Irecê, BA & J1-6, J1-7, J1-8, J1-9, J1-10 \\
Superfícies cársticas & Santa Maria da Vitória, BA & J2-6, J2-7, J2-8, J2-9, J2-10 \\
Bacias sedimentares & Jeremoabo, BA & I1-9, I1-10, I1-11, I1-12 \\
Maciços e serras altas & Brotas Macaúbas, BA & S1-6, S1-7, S1-8, S1-9 \\
Maciços e serras baixas & Sítio dos Moreiras, PE & T2-6, T2-7, T2-10 \\
Serrotes, inselbergues e maciços residuais & Japi, RN & U1-7, U1-8, U1-9, U1-10 \\
\hline
\end{tabular}


As amostragens para coleta das folhas foram realizadas entre janeiro e março de 2006. As folhas utilizadas para a extração de DNA foram armazenadas em freezer a $-80^{\circ} \mathrm{C}$.

O DNA foi extraído segundo Doyle \& Doyle (1990), modificado para 6.000 e $10.000 \mathrm{rpm}$, na primeira e na segunda centrifugações, respectivamente; beta-mercaptoetanol a $2 \%$ e incubação a $60^{\circ} \mathrm{C}$, durante 30 min, para todas as amostras. Após a adição do tampão Tris-EDTA, a solução de DNA foi tratada com RNase para remover RNAs co-isolados. A quantificação e a integridade do DNA foram verificadas em gel de agarose, seguida da diluição do DNA genômico para $40 \mathrm{ng} \mu \mathrm{L}^{-1}$.

Aproximadamente $200 \mathrm{ng}$ de DNA, de cada material genético, foi duplamente digerido com 0,65 unidade das endonucleases EcoRI e MseI, por 2,5 horas. A programação do termociclador para amplificações pré-seletivas consistiu de 20 ciclos de $94^{\circ} \mathrm{C}$, durante $30 \mathrm{~s}$, a $56^{\circ} \mathrm{C}$ durante $1 \mathrm{~min}$ e a $72^{\circ} \mathrm{C}$ durante $1 \mathrm{~min}$. Cada reação foi, então, diluída 20 vezes em tampão TE. Foram realizadas reações seletivas de amplificação para o volume final de $10 \mu \mathrm{L}$, de acordo com o protocolo: $0,2 \mu \mathrm{M}$ do iniciador da EcoRI, $0,3 \mu \mathrm{M}$ do iniciador da Msel, 0,2 mM de dNTPs, 1x tampão de PCR (100 mM Tris- $\mathrm{HCl}$ (pH 8,3), $500 \mathrm{mM} \mathrm{KCl}), 2,5 \mathrm{mM}$ de $\mathrm{MgCl} 2$, 0,5 unidades de Taq DNA polimerase e $2 \mu \mathrm{L}$ do DNA pré-amplificado. A programação do termociclador, para as amplificações seletivas, consistiram de um ciclo de $94^{\circ} \mathrm{C}$, seguido de $65^{\circ} \mathrm{C}$ durante 30 s e de $72^{\circ} \mathrm{C}$ durante $60 \mathrm{~s}$, repetidos 13 vezes e com a temperatura de anelamento de $65^{\circ} \mathrm{C}$ diminuída em $0,7^{\circ} \mathrm{C}$ em todo ciclo subseqüente; 23 ciclos a $94^{\circ} \mathrm{C}$ por $30 \mathrm{~s}$, $56^{\circ} \mathrm{C}$ durante $30 \mathrm{~s} \mathrm{e} 72^{\circ} \mathrm{C}$ durante $1 \mathrm{~min}$. As reações foram aquecidas durante $3 \mathrm{~min}$ a $94^{\circ} \mathrm{C}$, em presença de formamida, e foram imediatamente colocadas sob o gelo antes da aplicação nos géis de poliacrilamida. Os géis foram corados com nitrato de prata, conforme Creste et al. (2001). Todas as reações foram conduzidas no laboratório de genética da Embrapa Semi-Árido.

Foi determinado o número médio de bandas, anotadas por combinação de iniciador, bem como a percentagem de bandas polimórficas. $\mathrm{O}$ índice de similaridade de Jaccard foi utilizado, para se estimar a similaridade genética entre os indivíduos das espécies estudadas, por meio do programa NTSYS (Rohlf, 1989) ou do procedimento Distance (SAS Institute, 2004). A matriz de similaridade foi usada para a construção do dendrograma, pelo método de UPGMA, com auxílio do programa NTSYS (Rohlf, 1989), e para a construção de gráfico de escala multidimensional (SAS Institute, 2004). A avaliação do ajuste do dendrograma foi realizada pela correlação co-fenética, ou seja, comparando-se a matriz co-fenética com a matriz das similaridades genéticas.

A análise da variância de dados moleculares (AMOVA) foi realizada pela decomposição total nas suas componentes, entre e dentro de populações (ecorregiões), por meio das distâncias ao quadrado, conforme Excoffier et al. (1992), com o auxílio do programa Arlequim (Huff et al., 1993; Excoffier et al., 2005). A significância dessas estimativas foi obtida pelo método de randomização com 1.000 permutações.

\section{Resultados e Discussão}

Foram obtidos 141 e 58 fragmentos polimórficos e monomórficos, respectivamente, em 14 combinações de iniciadores (CP) EcoRl/Msel de AFLP, com média de 10 e 4,1 fragmentos polimórficos e monomórficos por combinações de iniciadores, respectivamente; as bandas polimórficas corresponderam a $71 \%$ do total de fragmentos amplificados. As combinações de iniciadores produziram os seguintes números de bandas: E-ACA/M-CAC (07), E-ACA/M-CTG (11), E-AAA/M-CTG (14), E-ACC/M-CAA (09), E-AAG/M-CTG (8), E-ACG/M-CAC (3), E-ATT/M-CAC (08), E-ACC/M-CTC (07), E-AAG/M-CTA (11), E-ACA/ M-CTG (08), E-AAC/M-CTG (13), E-AGC/M-CCC (12), E-AAA/M-CTA (14) e E-AAA/M-CTC (16).

Foram anotadas apenas as bandas bem definidas, tendo-se evitado as bandas que apresentassem pequena diferença na posição no gel. A média de 15 fragmentos polimórficos de AFLP foi reportado por Vos et al. (1995), com marcação com $\mathrm{P}^{33}$, que é próximo do valor obtido no presente trabalho, tendo-se usado coloração com nitrato de prata.

A correlação entre o procedimento SAHN e o coeficiente de similaridade da matriz, usando o procedimento MXCOMP do NTSYS (Rohlf, 1989), foi de 0,96 , o que indica que o dendrograma produzido (Figura 1) foi uma boa representação dos 141 fragmentos de AFLP. A dispersão dos indivíduos na escala bi-dimensional, segundo a técnica da escala multidimensional (MDS), resultou em ausência de adequação ou de não-ajuste de 0,25 (Figura 2). 
Foram observados agrupamentos específicos para seis regiões ecogeográficas: superfícies retrabalhadas (Anagé, BA), bacias sedimentares (Jeremoabo, BA), superfícies cársticas (Irecê, BA), maciços e serras baixas (Sítio dos Moreiras, PE), superfícies cársticas (Santa Maria da Vitória, BA) e depressão sertaneja (Ichu, BA). Nove dos 13 indivíduos amostrados em três regiões ecogeográficas - da unidade de paisagem superfícies retrabalhadas (Porteirinha, MG, Anagé, BA e Jacobina, BA) - formaram agrupamento específico, apesar das barreiras geográficas entre elas. Nas demais nove regiões ecogeográficas, apesar de se ter observado grande similaridade para alguns pares de indivíduos, não foram constatados agrupamentos específicos por local de amostragem (Figuras 1 e 2).

A ecorregião de Ichu, BA (depressão sertaneja) apresentou os indivíduos mais divergentes, com similaridade de apenas $28 \%$ em relação aos demais indivíduos do umbuzeiro (Figuras 1 e2). Essa ecorregião está localizada próximo da região de transição, entre o Semi-Árido e a Zona da Mata do Recôncavo Baiano, e é possível que algum tipo de especiação possa estar ocorrendo ali.

$\mathrm{O}$ conjunto desses resultados indica que a variabilidade genética do umbuzeiro não está uniformemente dispersa no Semi-Árido (Figuras 1 e 2); as barreiras geográficas ou as condições edafoclimáticas têm limitado o acasalamento e a freqüência dos alelos entre as populações amostradas. Esses resultados são diferentes dos obtidos por Santos (1997), que concluiu em estudo similar ao presente, com base em caracteres fenotípicos, que a variabilidade do umbuzeiro encontrase uniformemente distribuída no Semi-Árido brasileiro. No entanto, caracteres fenotípicos são extremamente

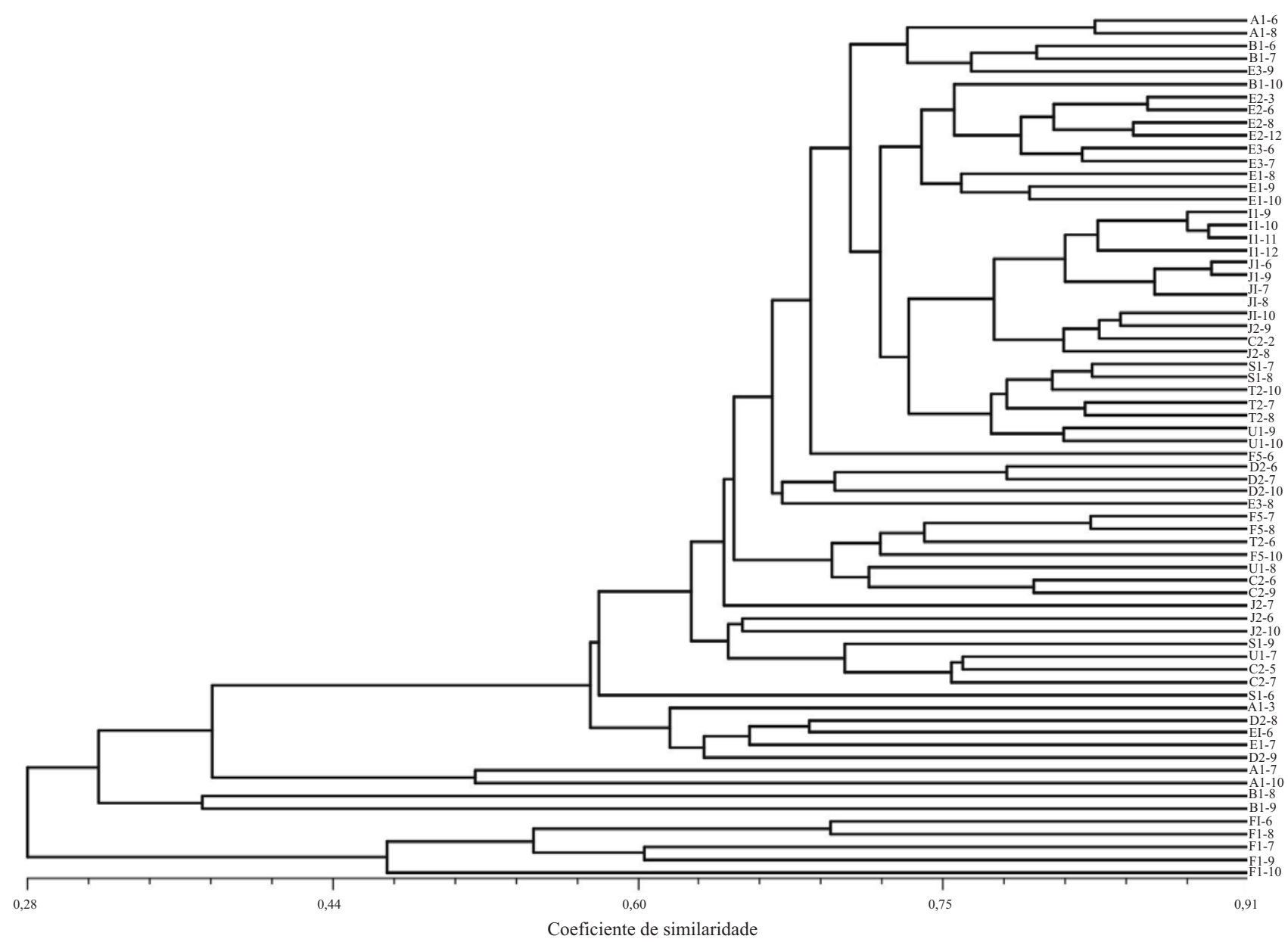

Figura 1. Dendrograma UPGMA do coeficiente de Jaccard entre 68 indivíduos de umbuzeiro (Spondias tuberosa), amostrados em 15 regiões ecogeográficas do Semi-Árido, com base em 141 marcadores AFLP (EcoRI/Msel). Valor cofenético = 0,96. 
influenciados pelo ambiente e, portanto, não são os mais indicados para estudos de dispersão genética.

A ausência de relações entre distância genética e regiões ecogeográficas tem sido reportada quanto aos caracteres influenciados pelas condições ambientais, como os fenotípicos, em Stipa lagascae e Artocarpus heterophyllus (Visser \& Reheul, 2001; Jagadeesh et al., 2007) ou em espécies submetidas a longo processo de seleção, como Solanum tuberosum (Rio et al., 2004), enquanto relações positivas entre distâncias genéticas e regiões ecogeográficas têm sido reportadas quanto a populações analisadas com marcadores moleculares, como Cicer arietinum (Abbo et al., 2003), Stylosanthes macrocephala (Barros et al., 2005), Heritiera littoralis (Jian et al., 2004), Amburana cearensis, Myracrodruon urundeuva, Schinopsis brasiliensis (Santos et al., 2007) e Brassica spp. (Watson-Jones et al., 2006).

Freitas et al. (2005) analisaram, por meio de AFLP, populações estabelecidas de M. urundeuva,

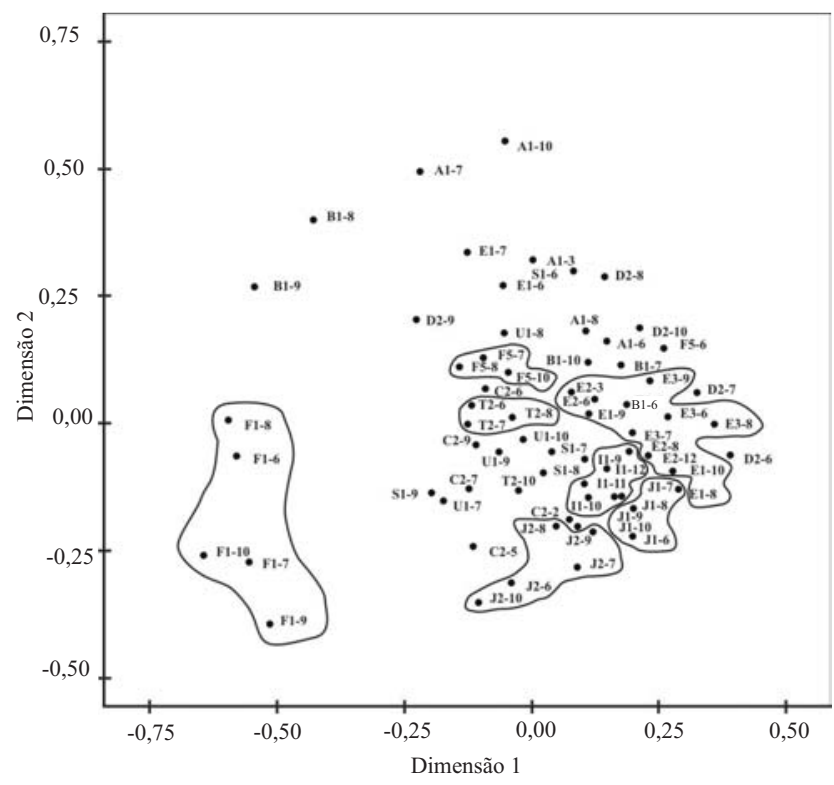

Figura 2. Escala multidimensional de 141 marcas polimórficas de AFLP, de 68 indivíduos de umbuzeiro coletados em 15 regiões ecogeográficas do Semi-Árido brasileiro. Valor da falta de ajustamento: 0,25. e encontraram maior similaridade genética entre progênies derivadas de árvores próximas, o que indica que a população original deve ser geneticamente estruturada. Do ponto de vista biológico, espera-se que as variações edafoclimáticas e as barreiras geográficas influenciem na variabilidade genética de uma dada espécie, conforme Maxted et al. (1995). Estudos da variabilidade genética em populações naturais de plantas, em regiões tropicais, têm demonstrado que estas preservam grande variabilidade dentro das populações (Paiva, 1998).

Como destacado por Reis \& Grattapaglia (2004), espera-se de espécies que apresentam comportamento alógamo, como o umbuzeiro, que menor variabilidade seja encontrada dentro de áreas do que entre áreas, o que deve ser comprovado em agrupamentos específicos de indivíduos amostrados numa mesma região, como observado neste trabalho.

A estimativa da variação entre ecorregiões foi 0,3138 $\left(\hat{\phi}_{\mathrm{ST}}\right)$, considerada alta. Esta estimativa sugere que esta espécie possui fluxo restrito, menos que um migrante por geração $(\mathrm{Nm}=0,567)$ e grande variabilidade entre as populações (ecorregiões) (Tabela 2). Apesar de ser uma espécie com tendência à alogamia (Souza, 2000), o fluxo gênico entre as populações é pequeno e considerado restrito, provavelmente em conseqüência da antropização das áreas estudadas.

Mariot (2000) analisou a estrutura genética de populações naturais de Piper cernnum e observou que a diferenciação genética, entre quatro populações da Mata Atlântica, foi elevada (FST =0,29), com forte estruturação espacial. $\mathrm{O}$ autor atribui a diferenciação encontrada ao efeito fundador das populações, visto ser esta uma espécie pioneira, que coloniza clareiras dentro da floresta.

Ao estudar pimenta longa, em áreas antropizadas no Estado do Acre, Wadt (2001) avaliou a estrutura genética de 13 populações naturais de Piper hispidinervum, por meio de 44 locos de marcadores RAPD. O autor verificou que a variabilidade dentro da população foi alta: $\theta p=0,25$. Duas regiões, com dois grupos

Tabela 2. Análise de variância molecular (AMOVA) e estimativa de fluxo gênico (Nm) da população de umbuzeiro, calculado pelo método de Wright (1951).

\begin{tabular}{lccccc}
\hline Fonte de variação & GL & SQ & Total da variação (\%) & $\mathrm{P}^{(1)}$ & Estatística $\phi$ \\
\hline Entre populações & 14 & 678.729 & 31,38 & $<0,001$ & $\phi_{\text {ST }}=0,3138$ \\
Dentro de populações & 53 & 836.550 & 68,62 & $<0,001$ & $1-\phi_{\text {ST }}=0,6862$ \\
\hline Total & 67 & 1.515 .279 & - & - & - \\
\hline
\end{tabular}

${ }^{(1)}$ Probabilidade com base em 1.000 permutações. 
distintos, representaram o Alto e o Baixo Acre, com valor de $\hat{\phi}_{\mathrm{ST}}=0,2061$. Zucchi et al. (2005) verificaram, com marcadores RAPD, em uma arbórea frutífera do Cerrado, Eugenia dysenterica, que a estimativa $\hat{\phi}_{\mathrm{ST}}=0,2703$ foi alta, e que tem fluxo restrito entre as populações, em razão da antropização.

Os resultados obtidos neste trabalho indicam que os indivíduos apresentam diferenças em razão da região de amostragem, que os indivíduos de uma dada região apresentam menor dissimilaridade e que a variabilidade genética do umbuzeiro não está uniformemente distribuída por todo o Semi-Árido brasileiro. Nesse cenário, são necessários: maior número de áreas para conservação in situ da espécie e a amostragem de um número suficiente de germoplasma-semente, em maior número de regiões ecogeográficas, para a conservação ex situ da variabilidade genética da espécie. Esses dados estão de acordo com a análise de variância molecular, que mostrou grande variação entre populações de umbuzeiro $\left(\hat{\phi}_{\mathrm{ST}}=0,3138\right)$, o que indica que se deve coletar maior número de populações, para se ter maior visibilidade da diversidade da espécie.

Apesar de seu potencial e de ser endêmico do SemiÁrido brasileiro, o umbuzeiro é considerado uma espécie ameaçada de extinção em alguns estados do Brasil (São Paulo, 1992). A definição e execução de estratégias de prospecção, preservação e utilização da variabilidade genética da espécie são necessárias e urgentes.

\section{Conclusões}

1. A variabilidade genética do umbuzeiro não está uniformemente distribuída no Semi-Árido brasileiro, mas sim em regiões ecogeográficas.

2. A variabilidade genética do umbuzeiro entre populações é alta; deve-se amostrar um maior número de populações para a conservação da espécie.

3. Devem ser consideradas estratégias que resultem no estabelecimento de um maior número de áreas, para preservação in situ, ou amostragens de um menor número de indivíduos, em várias unidades de paisagens, para preservação ex situ da variabilidade genética do umbuzeiro.

\section{Agradecimentos}

Ao Banco do Nordeste do Brasil, pelo apoio financeiro.

\section{Referências}

ABBO, S.; BERGER, J.; TURNER, N.C. Evolution of cultivated chickpea: four bottlenecks limit diversity and constrain adaptation. Functional Plant Biology, v.30, p.1081-1087, 2003.

BARROS, A.M.; FALEIRO, F.G.; KARIA, C.T.; SHIRATSUCHI, L.S.; ANDRADE, R.P. de; LOPES, G.K.B. Variabilidade genética e ecológica de Stylosanthes macrocephala determinadas por RAPD e SIG. Pesquisa Agropecuária Brasileira, v.40, p.899-909, 2005.

CRESTE, S.; TULMANN NETO, A.; FIGUEIRA, A. Detection of single sequence repeat polymorphisms in denaturing polyacrylamide sequencing gels by silver staining. Plant Molecular Biology Reporter, v.19, p.299-306, 2001.

DOYLE, J.J.; DOYLE, J.L. Isolation of plant DNA from fresh tissue. Focus, v.12, p.13-15, 1990.

EXCOFFIER, L.; LAVAL, G.; SCHNEIDER, S. Arlequin ver. 3.0: an integrated software package for population genetics data analysis. Evolutionary Bioinformatics Online, v.1, p.47-50, 2005.

EXCOFFIER, L.; SMOUSES, P.E.; QUATTRO, J.M. Analysis of molecular variance inferred from metric distances among DNA haplotypes: application to human mitocondrial DNA restriction data. Genetics, v.131, p.479-491, 1992.

FREITAS, M.L.M.; AUKAR, A.P. de A.; SEBBENN, A.M.; MORAES, M.L.T. de; LEMOS, E.G.M. Variabilidade genética intrapopulacional em Myracrodruon urundeuva Fr. All. por marcador AFLP. Scientia Forestalis, v.68, p.21-28, 2005.

HUFF, D.R.; PEAKALL, R.; SMOUSE, P.E. RAPD variation within and among natural populations of outcrossing buffalograss (Buchoë dactuloides (Nutt.) Elgen). Theoretical and Applied Genetics, v.86, p.927-934, 1993.

JAGADEESH, S.L.; REDDY, B.S.; BASAVARAJ, N.; SWAMY, G.S.K.; KIRANKUMAR, G.; LAXMINARAYAN, H.; RAGHAVAN, G.S.V.; KAJJIDONI, S.T. Inter tree variability for fruit quality in jackfruit selections of Western Ghats of India. Science Horticulture, v.112, p.382-387, 2007.

JIAN, S.G.; TANG, T.; ZHONG, Y.; SHI, S.H. Variation in intersimple sequence repeat (ISSR) in mangrove and non-mangrove populations of Heritiera littoralis (Sterculiaceae) from China and Australia. Aquatic Botany, v.79, p.75-86, 2004.

MARIOT, A. Distribuição da diversidade genética e aspecto da fenologia e dispersão de sementes de pariparoba (Piper cernuum Vell. - Piperaceae). 2000. 110p. Dissertação (Mestrado) - Universidade Federal de Santa Catarina, Florianópolis.

MAXTED, N.; VAN SLAGEREN, M.W.; RIHAN, J.R. Ecogeographic surveys. In: GUARINO, L.; RAO, V.R.; REID, R. (Ed.). Collecting plant genetic diversity. Cambridge: $C A B$ International, 1995. p.255-285.

MILLER, A.; SCHAAL, B. Domestication of a Mesoamerican cultivated fruit tree, Spondias purpurea. Proceedings of the National Academy of Science of the United States of America, v.102, p.12801-12806, 2005.

PAIVA, J.R. Melhoramento genético de espécies agroindustriais na Amazônia: estratégias e novas abordagens. Brasília: EmbrapaSPI; Fortaleza: Embrapa-CNPAT, 1998. 135p. 
PRADO, D.E.; GIBBS, P.E. Patterns of species distributions in the dry seasonal forests of South America. Annals of the Missouri Botanic Garden, v.80, p.902-927, 1993.

REIS, A.M.M.; GRATTAPAGLIA, D. RAPD variation in a germplasm collection of Myracrodruon urundeuva (Anacardiaceae), an endangered tropical tree: recommendations for conservation. Genetic Resources and Crop Evolution, v.51, p.529-538, 2004.

RIO, A.H. del; BAMBERG, J.B.; HUAMAN, Z.; SALAS, A.; VEGA, S.E. Association of ecogeographical variables and RAPD marker variation in wild potato populations of the USA. Crop Science, v.41, p.870-878, 2004.

ROHLF, F.J. NTSYS-PC: numerical taxonomy and multivariate analysis system. New York: Exeter Software, 1989. (Version 1.80).

SANTOS, C.A.F. Dispersão da variabilidade fenotípica do umbuzeiro no Semi-Árido brasileiro. Pesquisa Agropecuária Brasileira, v.32, p.923-930, 1997.

SANTOS, C.A.F.; CAVALCANTI, N. de B.; NASCIMENTO, C.E.; ARAÚJO, F.P. de; LIMA FILHO, J.M.P.; ANJOS, J.B. dos; OLIVEIRA, V.R. de. Umbuzeiro: pesquisas, potenciais e desafios. In: ROMÃO, R.R.; RAMOS, S.R.R. (Org.). Recursos genéticos vegetais no Estado da Bahia. Feira de Santana: UEFS, 2005. p.69-81.

SANTOS, C.A.F.; OLIVEIRA, V.R.; KIILL, L.H.P.; SÁ, I.I.S. Variabilidade genética, com base em marcadores RAPD, de três espécies arbóreas ameaçadas de extinção no Semi-Árido brasileiro. Scientia Forestalis, v.74, p.37-44, 2007.

SÃO PAUlO (Estado). Secretaria do Meio Ambiente. Brasil'92: perfil ambiental e estratégias. São Paulo: Secretaria do Meio Ambiente, 1992. 218p.
SAS INSTITUTE. SAS/STAT 9.1: user's guide. Cary: SAS Institute, 2004.

SOUZA, J.C. de. Variabilidade genética e sistema de cruzamento em populações naturais de umbuzeiro (Spondias tuberosa Arr. Cam.). 2000. 86p. Tese (Doutorado) - Universidade Federal de Viçosa, Viçosa.

VISSER, M.; REHEUL, D. Restoring depleted Tunisian drylands with native steppic species: where should we source the seeds? Genetic Resources and Crop Evolution, v.48, p.567-578, 2001.

VOS, P.; HOGERS, R.; BLEEKER, M.; REIJANS, M.; VAN DE LEE, T.; HORNES, M.; FRIJTERS, A.; POT, J.; PELEMAN, J.; KUIPER, M.; ZABEAU, M. AFLP: a new technique for DNA fingerprinting. Nucleic Acids Research, v.23, p.4407-4414, 1995.

WADT, L.H.O. Estrutura genética de populações naturais de pimenta-longa (Piper hispidinervum C. DC.) visando seu uso e conservação. 2001. 95p. Tese (Doutorado) - Escola Superior de Agricultura Luiz de Queiroz, Piracicaba.

WATSON-JONES, S.J.; MAXTED, N.; FORD-LLOYD, B.V. Population baseline data for monitoring genetic diversity loss for 2010: a case study for Brassica species in the UK. Biological Conservation, v.132, p.490-499, 2006.

WRIGHT, S. The genetical structure of populations. Annals of Eugenics, v.15, p.323-354, 1951.

ZUCCHI, M.I.; PINHEIRO, J.B.; CHAVES, L.J.; COELHO, A.S.G.; COUTO, M.A.; MORAIS, L.K. de; VENCOVSKY, R. Genetic structure and gene flow in Eugenia dysenterica natural populations. Pesquisa Agropecuária Brasileira, v.40, p.975-980, 2005.

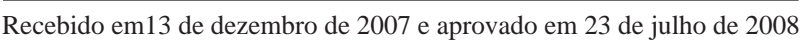

